\title{
Short term effectiveness and experiences of a peer guided web-based self- management intervention for young adults with juvenile idiopathic arthritis
}

Judy Ammerlaan ${ }^{1,6^{*}}$ (D), Harmieke van Os-Medendorp² ${ }^{2}$ Nienke de Boer-Nijhof ${ }^{1}$, Lieske Scholtus ${ }^{1}$, Aike A. Kruize ${ }^{3}$, Philomine van Pelt ${ }^{4,5}$, Berent Prakken ${ }^{5}$ and Hans Bijlsma ${ }^{3}$

\begin{abstract}
Background: A web-based self-management intervention guided by peer-trainers was developed to support young adults' self-management in coping with Juvenile Idiopathic Arthritis (JIA). To investigate its effectiveness, a randomized controlled trial (RCT) was conducted. In addition, the content of the chat and participants' goals were studied to identify underlying processes.

Methods: An RCT with a six-month follow up period was conducted among 72 young adults with JIA, aged between 16 and 25 years old, randomly assigned to the intervention or to the usual care control group. After 24 weeks, in both groups 24 participants completed all measurements. Intentions to treat analyses were carried out by means of linear mixed models for longitudinal measurements. With self-efficacy as primary outcome, self-management, disease activity, quality of life, absenteeism of school/work, health care medication use and adherence to the intervention were studied. The participants' goals, personal achievements, interactions on the chat, and their appreciation of the intervention were analyzed using thematic analyses.

Results: No significant differences were found on self-efficacy, quality of life, and self-management between the participants of the control group and the intervention group. In the intervention group, modeling and sharing experiences were the most recognized themes. Fifty-five goals were formulated and divided into the following categories: improvement and maintaining balance, setting and recognizing boundaries, communicating and coping with incomprehension. Adherence, appreciation of the own learning experience, and personal achievements were rated positively.
\end{abstract}

Conclusion: The web-based intervention did not lead to an improvement of self-efficacy. However, additional qualitative analyses showed that the intervention was appreciated and valuable for the participants. More research is needed on how to measure the added value of this intervention compared to the usual care.

Trial registration: Trial registration number NTR4679.

Keywords: Young adults, Juvenile idiopathic arthritis, Peer-guided, Self-management, Web-based intervention, Effectiveness, Short-term, Experiences

\footnotetext{
* Correspondence: j.ammerlaan@umcutrecht.nl

'Department Rheumatology \& Clinical Immunology HPN D02.244, University

Medical Center Utrecht, PO Box 85090, 3508 GA Utrecht, the Netherlands

${ }^{6}$ Department Rheumatology \& Clinical Immunology, HPN D02.244, University

Medical Center Utrecht, PO Box 85500, 3500 GA Utrecht, the Netherlands

Full list of author information is available at the end of the article
} 


\section{Background}

eHealth interventions are developed and offered more and more to patients with chronic diseases in order to improve their self-management [1-3]. Since young adults are one of the most active groups of internet users, eHealth interventions like portals and self-management support programs may also be promising options for patients with Juvenile Idiopathic Arthritis (JIA) [1, 2, 4-12]. Furthermore, traditional health care services do not always suit the needs and problems of young adults, aged between 16 and 25 years, with JIA [8-13]. In the Western world, the reported incident of JIA varies between 1 to 22 cases per 100.000 children, with a prevalence of 8 to 150 cases per 100.000 [13]. The disease and its treatment put extensive demands on children and young adults as well as on their parents, due to precisely-scheduled daily medication requirements, regular physical exercise regimes and regular visits to the pediatrician or rheumatologist $[14,15]$. Most of these young adults still experience problems well into their adult years with on-going medical treatment and significant disability [12-14]. Like other young adults, young adults with JIA have to develop their own identity and independence, but for them, the path towards adulthood is a lot bumpier $[11,15,16]$. As they become more independent, they will gradually become more responsible for their own illness and its treatment; they will become selfmanagers. Enhanced self-management may prevent disease exacerbation and facilitate a successful transition into adult care $[2,9,17]$ and can be best described as 'the individual's ability to manage the symptoms, treatment, physical and psychological consequences and life style changes, inherent to living with a chronic illness as JIA' [18]. At the University Medical Center Utrecht (UMC Utrecht), a web-based self-management intervention was developed in close cooperation with young adults, the Dutch Youth Network for young people with arthritis (YouthRwell.com), and both multidisciplinary teams of the child and adult rheumatology department [19].

The web-based intervention, which is called "Challenge your arthritis", www.reumauitgedaagd.nl/jongeren (URL in Dutch) is based on the self-efficacy theory of Bandura [20] where self-efficacy stands for the confidence in one's own ability to achieve indented results, such as self-management. Self-management may be enhanced by increasing self-efficacy [18] through practicing, observing others (modeling), meeting beliefs of others and by interpretation of physiological and emotional status. All these elements are embedded in the web-based intervention.In order to display pro-active behavior one needs to set personal goals prior to starting the program [21]. Therefore, goal-setting is a crucial element of the intervention. The intervention is led by young peer trainers in the age range of 20-30 years who suffer from arthritis themselves. They are recruited and selected through assessments and interviews conducted by the Dutch Rheumatism Patient League (DRPL). Finally, the peer leader was trained through a train-thetrainer educational program by the UMC Utrecht and a professional coaching organization (Work21.nl). This program consisted of following the training as a participant, learning about the different themes, and studying training skills.

The first draft of the intervention was evaluated on items of perceived usefulness, perceived ease of use, user acceptance and adherence in 12 young adults and 4 peer trainers, and appeared to be feasible, especially in dealing with problems in daily life [19]. Although the intervention is thought to be a practical aid in health practices, a randomized controlled trial (RCT) was conducted to investigate its effectiveness on self-efficacy, self-management, and quality of life. In addition, thematic analysis [22] within the intervention group was carried out to explore the interaction in the Chat, the goals the participants set, and the appreciation of the intervention itself.

\section{Methods \\ Design}

A RCT, with a six-month follow up period was conducted among young adults with JIA, who were being treated at the transition outpatient clinics of the UMC Utrecht and the Erasmus Hospital Rotterdam in the Netherlands. Participants of the intervention group were given access to the web-based self-management intervention. Qualitative thematic content analyses [22] were then used to explore the interactions in the Chat, the content of the formulated goals, participants' personal achievements regarding their goals, and the appreciation of the intervention itself. The control group was a waiting list group, who were granted access to the webbased intervention after 6 months.

\section{Participants}

Young patients, aged between 16 and 25 years, were eligible to participate if they were a) diagnosed with JIA b) abled to speak and read Dutch, c) had access to the internet and a mobile phone, and d) hadn't participated in a self-management intervention before. Participants were recruited by their pediatrician/rheumatologist at the transition outpatient clinic. After information, informed consent had been obtained - for the participants $<18$ years, also from their parents - the participants were asked to fill in online baseline measurements, prior to randomization.

\section{Randomization}

Because the intervention was group-based with six participants per group, randomization was carried out each 
time 12 participants were included in the study. Since more women are diagnosed with a rheumatic disease compared to men, stratified block, randomization for the factor 'gender' to equally divide 'men' and 'women' among both groups, using a computerized intervention with an automated process, was conducted with no interference from the investigator. After randomization, the participants (and the parents of the participants $<18$ years) received the allocated condition by email and post.

\section{Intervention and control group}

Both the control group and the intervention group received the usual care, based on medical guidelines [23], consisting of a 3 monthly visit to the transition outpatient clinic where medical problems, questions, and treatment plans were discussed and an assessment of the disease activity was carried out by the pediatrician/ rheumatologist or the transition nurse. Furthermore, the transition nurse also focused on problems and questions on dealing with the consequences of having JIA and coordinated the process of transition. Both control and intervention group were allowed to use information presented on the website jong-en-reuma.nl (in Dutch). This website contains information about medical issues and themes such as dealing with the consequences of having a rheumatic disease, feeling depressed, exercise, work and study, relationships and intimacy [6].

\section{The intervention group}

In addition to the usual care, the intervention group started within 1 month, after randomization, with the web-based self-management intervention. Challenge your arthritis consists of password-protected, interactive webbased self-management instruction with three components: a Chat section, home exercises and a discussion board. Once a week, the group (six participants, two trainers) had a planned group Chat for a maximum of $90 \mathrm{~min}$. Within the Chat, the weekly theme was clarified, goals were set and the participants were allowed to practice, ask questions, give and receive feedback, play a game or watch a real life story video based on the weekly theme. The weekly themes were based on the six themes of the intervention and outlined in Table 1. The home exercises were also discussed and evaluated. After the Chat, participants were allowed to work through the intervention at any time at home and do the exercises (1 hour per week). The home exercises consisted, for example, of reading information, watching a video, or practicing communication skills at school or work. The content of the home exercises was related to the weekly theme or their personal goals. The Chat and exercises, both created with input of young adults themselves, were supported by short videos in which young adults with a rheumatic diseases or a member of the multidisciplinary team spoke about their
Table 1 Themes and content of the web-based self-management intervention Challenge your arthritis

\begin{tabular}{|c|c|}
\hline Themes & Contents \\
\hline Are you a self-manager? & $\begin{array}{l}\text { - introducing yourself, get in touch with the } \\
\text { group } \\
\text { - what do you (want to) know about your } \\
\text { disease? } \\
\text { - capacities and talents } \\
\text { - goal setting and action planning }\end{array}$ \\
\hline $\begin{array}{l}\text { Friends, family and } \\
\text { communication }\end{array}$ & $\begin{array}{l}\text { - communication strategies } \\
\text { - communication with school, friends, work, } \\
\text { parents, health care providers } \\
\text { - giving and receiving feedback } \\
\text { - setting boundaries }\end{array}$ \\
\hline Feeling blue & $\begin{array}{l}\text { - receiving therapies (treatment, medication) } \\
\text { - pain, fatigue, feeling blue } \\
\text { - asking and giving help } \\
\text { - relaxation }\end{array}$ \\
\hline Sport and exercises & $\begin{array}{l}\text { - being active } \\
\text { - motion and physical activity } \\
\text { - maintain your plans }\end{array}$ \\
\hline Relations and Intimacy & $\begin{array}{l}\text { - body images and thoughts } \\
\text { - having a relationship } \\
\text { - having sex } \\
\text { - thinking about kids, pregnancy, heredity }\end{array}$ \\
\hline $\begin{array}{l}\text { Having control over your } \\
\text { life and arthritis }\end{array}$ & $\begin{array}{l}\text { - evaluation of your personal goals; how to } \\
\text { move on? } \\
\text { - being responsible and making choices } \\
\text { - celebration and saying goodbye }\end{array}$ \\
\hline
\end{tabular}

experiences with JIA. In addition, a discussion board was used by trainers and participants to offer encouragement and share tips.

For 6 weeks, participants worked chronologically through the intervention using the six weekly themes (Table 1). On average, the total time investment for the intervention was $12 \mathrm{~h}$ in a 6-week-period per patient.

\section{Outcome measures}

In this study quantitative and qualitative outcome measures were collected online with questionnaires, text messages, self-reported by participants. All outcome measures were collected at baseline, 3 and 6 months after randomization. Demographic and disease related variables were collected at baseline, supplemented with data from the medical record. Internet skills were assessed with a short questionnaire on general and health related use of the internet, similar to the questionnaire used in the study of van Pelt [7] on the use and relevance of health related internet sites by patients with JIA. A transcript of the interactions was available for thematic analyses of goals, personal achievements, and appreciation of the intervention.

\section{Quantitative outcomes}

\section{Primary outcome measurement}

The Dutch Arthritis Self-efficacy Scale (Dutch- ASES) [24] was used to measure self-efficacy as a determinant 
of self-management behavior. This online questionnaire was translated from the German-ASES which showed an internal consistency of 0.90 in a similar study population. The translation process included repeated forwardbackward translation, an expert group opinion, and testing of the Dutch-ASES in the patient group $(n=12)$ to ensure content validity. The questionnaire contains eight items. For each item, respondents were asked to indicate on a scale from 1 (very unconfident) to 10 (highly confident) how confident they felt in bringing a situation to a good outcome. The mean score of the eight items was calculated where a higher score indicated a higher degree of self-efficacy.

\section{Secondary outcomes measurement}

The following secondary quantitative outcomes were assessed: self-management, quality of life, medication use, health care use, absenteeism of school or work, personal learning experiences, and adherence with the intervention.

The Dutch Health Education Impact Questionnaire (Dutch heiQ) [25] was used to measure self-management related outcomes. This online questionnaire was translated, culturally adapted and validated in a validation study [25] among adults suffering from a chronic illness, like arthritis. Results from this study showed an internal consistency of $0.67-0.85$ on the eight scales, comparable with the original English version [26] and was found to have robust psychometric properties, and to be user friendly and well understood. This Dutch heiQ consists of 40 questions, divided into eight independent scales which cover eight self-management domains: 'Positive and active engagement in life, 'Health directed activity', 'Skills and technique acquisition', 'Constructive attitudes and approaches', 'Self-monitoring and insight,' 'Health service navigation,' 'Social integration and support', and a reversed scale, 'Emotional distress'. Each scale is calculated a mean score $(\min 1, \max 4)$. A higher mean score indicates a higher degree of self-management in each domain, on each scale.

The Dutch Consensus Health Assessment Questionnaire Disability Index (HAQ-DI) [27] was assessed to measure the first dimension of quality of life (QoL); physical functioning. The second dimension of QoL was a combination of 4 patient reported outcomes: pain, fatigue, general well-being, and disease activity. This dimension was assessed with a Numerical Rating Scale (NRS) [28] from ' 0 ' to ' 10 ' (the higher the score, the more pain, fatigue, or disease activity and the worse general wellbeing). For 3 days in a row, on a fixed time, participants were asked to send their responses via a text message.

Medication and health care use were assessed by analyzing the medical patient record.
Medication was divided in the following categories: Disease Modifying Anti Rheumatic Drug (DMARD), Non Steroid Anti Inflammatory Drug (NSAID), Biologicals and use of paracetamol. Health care use was operationalized by counting the number of consultations to the pediatrician/rheumatologist/transition nurse and day-care center at the hospital. Absenteeism of school or work was assessed with one question (days of absenteeism of school last month, due to JIA) by a text message on one fixed moment.

At the end of the intervention, participants of the intervention group were asked to indicate with a score from 0 to 10 on a NRS how they rated their own learning experience. Also, in this group, adherence with the web-based intervention was measured by the researcher by counting the amount of total participation in the weekly Chat.

\section{Qualitative outcomes}

Interaction in the Chat, goals, personal achievements with regard to their goals, and appreciation of the intervention were explored using thematic analyses [22] within the intervention group. With thematic content analyses, relevant written fragments/transcripts are first categorized in main themes, related to the goals of the study and the intervention, and further categorized into sub-themes [29]. Results were discussed on several occasions and differences were discussed until consensus was reached.

\section{Statistical analysis \\ Quantitative analyses}

The consolidated Standards of Reporting Trials (CONSORT) statement [30] was used to present the results of this study. Quantitative data was entered into a SPSS data base. Based on the theoretical fundament of the intervention, it was hypothesized that participants of the intervention group would have a better result on selfefficacy, compared with the usual care control group participants. Sample size calculation, based on a previous study of Niedermann et al. [31], suggested that 72 patients were required to find a difference between both groups of 1.29 ( $s d$ 1.6) on self-efficacy, with a power of $80 \%$ and alpha of .05 and, an estimated loss of $30 \%$.

Demographic variables and absenteeism of school/ work, frequency of health care use and medication use were presented using descriptive analyses and frequency scores. Adherence of the intervention group in the Chat, and the indication score of their own learning was counted and displayed with a frequency score. Linear mixed models for longitudinal measurements were used to determine the effects on self-efficacy, self-management related outcomes and the effects on QoL scores for physical activity, pain, well-being, and fatigue and disease 


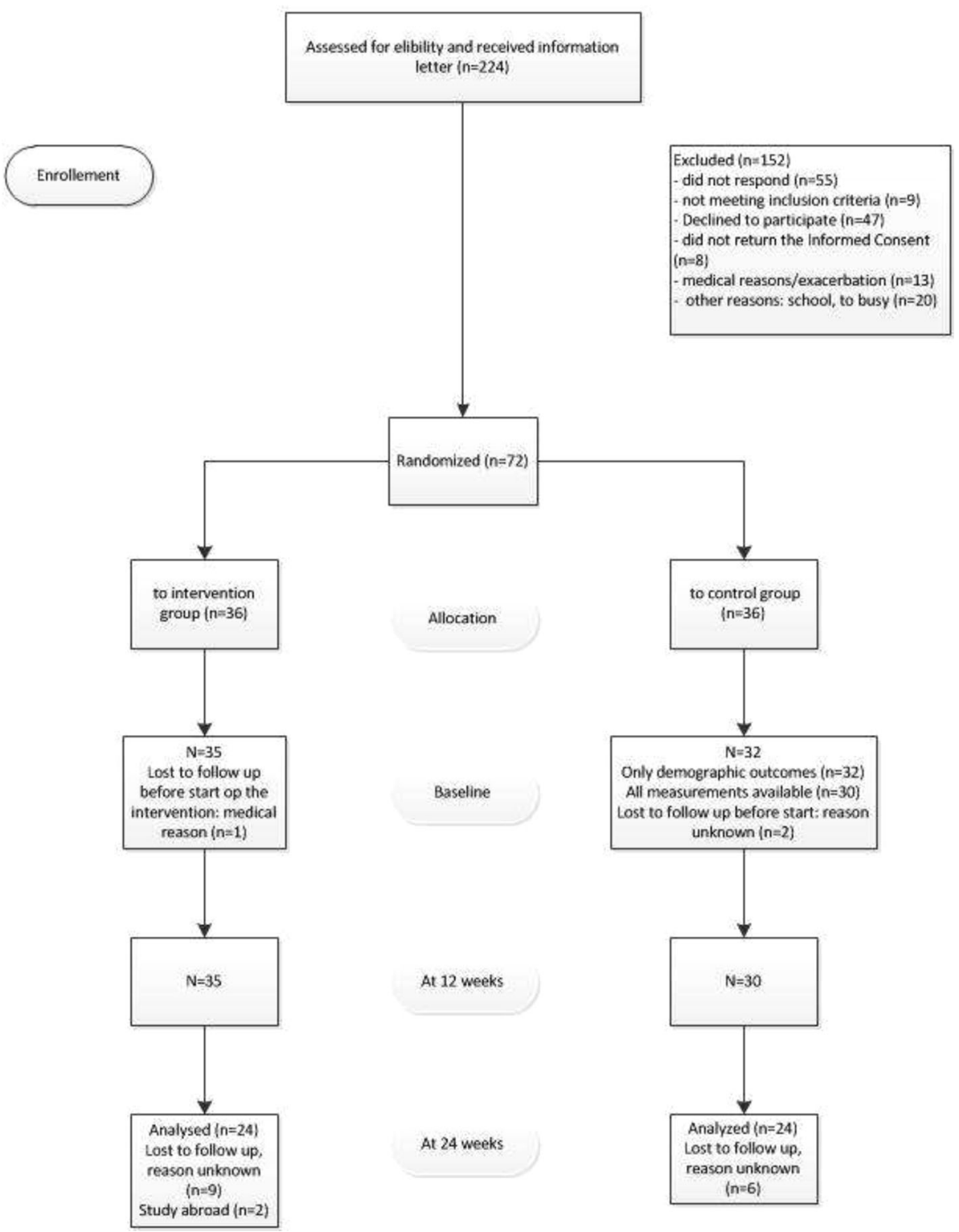

Fig. 1 Flowchart of the participants

activity. Linear mixed models is a statistical model especially used for repeated, longitudinal measures [32] and is a proven, reliable statistical procedure which deals with missing values.

Fixed effects for group, time and group versus time interaction were included in the model.

\section{Qualitative analyses}

All transcripts of the Chats were inserted into the program Nvivo (QSR International Pty LTD Version 10). To describe the interaction in the Chat, the transcripts were analyzed, using codes like modeling, mastering, verbal persuasion, goals, sharing experiences, emotional attitude and appreciation, derived from the self-efficacy theory and the elements of the intervention.

Relevant fragments within the transcripts related to goals, personal achievements and appreciation of the intervention were categorized independently by two members of the research group (JA and NdBN). Results were discussed until consensus was reached.

\section{Results}

A group of 224 young adults with JIA were found to be eligible to participate in this study and were invited. 152 were excluded of which the largest group (55/152) was 
Table 2 Baseline characteristics of the participants

\begin{tabular}{|c|c|c|c|}
\hline \multicolumn{4}{|l|}{ Baseline characteristics Intervention versus Control } \\
\hline Characteristic & Total group $(n=67)$ & Intervention group $(n=35)$ & Control group $(n=32)$ \\
\hline Gender - female n (\%) & $59(88 \%)$ & $29(83 \%)$ & $30(94 \%)$ \\
\hline Age, mean years (SD) & $19.1(2.7)$ & $19.2(2.7)$ & $19.1(2.9)$ \\
\hline \multicolumn{4}{|l|}{ Education level completed n (\%) } \\
\hline Primary education ${ }^{\mathrm{a}}$ & $15(22 \%)$ & $10(29 \%)$ & $5(16 \%)$ \\
\hline Intermediate vocational education ${ }^{\text {b }}$ & $35(52 \%)$ & $17(49 \%)$ & $18(56 \%)$ \\
\hline Bachelor or University & $17(25 \%)$ & $8(23 \%)$ & $9(28 \%)$ \\
\hline \multicolumn{4}{|l|}{ Civil status n (\%) } \\
\hline Living at home with parents & $53(79 \%)$ & $26(74 \%)$ & $27(84 \%)$ \\
\hline Living independently & $14(21 \%)$ & $9(26 \%)$ & $5(16 \%)$ \\
\hline \multicolumn{4}{|l|}{ Marital status n (\%) } \\
\hline Single & $61(91 \%)$ & $32(91 \%)$ & $29(91 \%)$ \\
\hline Living together & $3(5 \%)$ & $1(2 \%)$ & $2(6 \%)$ \\
\hline Married & $3(5 \%)$ & $2(6 \%)$ & $1(3 \%)$ \\
\hline \multicolumn{4}{|l|}{ Diagnosed disease n (\%) } \\
\hline Oligo-articular JIA & $14(21 \%)$ & $8(23 \%)$ & $6(19 \%)$ \\
\hline Poly-articular JIA & $24(36 \%)$ & $9(26 \%)$ & $15(47 \%)$ \\
\hline Systemic JIA & $8(12 \%)$ & $6(17 \%)$ & $2(6 \%)$ \\
\hline Other & $21(31 \%)$ & $12(34 \%)$ & $9(28 \%)$ \\
\hline Duration of the disease (years diagnosed, mean, SD) & $10.9(6.4)$ & $10.1(6,3)$ & $11.8(6.5)$ \\
\hline \multicolumn{4}{|l|}{ Frequency of internet use n(\%) } \\
\hline (Almost) daily & $62(93 \%)$ & $31(89 \%)$ & $31(97 \%)$ \\
\hline Several times a week & $3(5 \%)$ & $2(6 \%)$ & $1(3 \%)$ \\
\hline Few times a week & $1(2 \%)$ & $1(3 \%)$ & \\
\hline Rarely & $1(2 \%)$ & $1(3 \%)$ & \\
\hline \multicolumn{4}{|l|}{ Purpose use internet } \\
\hline \multicolumn{4}{|l|}{ Search health info n(\%) } \\
\hline Not & $3(5 \%)$ & $2(6 \%)$ & $1(3 \%)$ \\
\hline Yes, one single time & $30(45 \%)$ & $18(51 \%)$ & $12(38 \%)$ \\
\hline Yes, sometimes & $28(28 \%)$ & $11(31 \%)$ & $17(53 \%)$ \\
\hline Frequent & $6(9 \%)$ & $4(11 \%)$ & $2(6 \%)$ \\
\hline \multicolumn{4}{|l|}{ Forum visit health/arthritis } \\
\hline Not & $47(70 \%)$ & $23(66 \%)$ & $24(75 \%)$ \\
\hline Yes, one single time & $12(18 \%)$ & $7(20 \%)$ & $5(16 \%)$ \\
\hline Yes, sometimes & $6(9 \%)$ & $4(11 \%)$ & $2(6 \%)$ \\
\hline Frequent & $2(3 \%)$ & $1(3 \%)$ & $1(3 \%)$ \\
\hline \multicolumn{4}{|l|}{ Chat/e-mail with someone with arthritis } \\
\hline Not & $55(82 \%)$ & $27(77 \%)$ & $28(88 \%)$ \\
\hline Yes, one single time & $5(7 \%)$ & $4(11 \%)$ & $1(3 \%)$ \\
\hline Yes, sometimes & $2(3 \%)$ & $2(6 \%)$ & \\
\hline Frequent & $5(8 \%)$ & $2(6 \%)$ & $3(9 \%)$ \\
\hline
\end{tabular}

Visit weblog patient 
Table 2 Baseline characteristics of the participants (Continued)

\begin{tabular}{llll}
\hline Baseline characteristics Intervention versus Control & & & \\
\hline Characteristic & Total group $(n=67)$ & Intervention group $(n=35)$ & Control group $(n=32)$ \\
\hline Not & $55(82 \%)$ & $30(86 \%)$ & $25(78 \%)$ \\
Yes, one single time & $9(13 \%)$ & $2(6 \%)$ & $7(22 \%)$ \\
$\quad$ Yes, sometimes & $2(3 \%)$ & $2(6 \%)$ & $1(3 \%)$ \\
$\quad$ Frequent & $1(2 \%)$ & & $3.7(2.1)$ \\
Relevance internet in relation & & $3.1(2.7)$ & $3.0(2.5)$ \\
disease, Scale 1-10 (mean) (SD) & $3.0(2.5)$ & $3.1(2.6)$ & \\
peer support, Scale 1-10 (mean) (SD) & & &
\end{tabular}

SD standard deviation

a Lower vocational education, lower general secondary education

${ }^{b}$ higher general secondary education, pre-university education

unreachable by phone to give additional information or to check inclusion criteria. 47/152 declined to participate in the study after being informed that the intervention lasted 6 weeks and participation in all Chat sessions was mandatory (see Fig. 1). Finally, 72 participants with a mean age of 19 years old, most of them female (88\%) were randomized, equally divided into the intervention and the control group (see Table 2). Five participants (4 of the control group and 1 of the intervention group) did not fill in the baseline questionnaire, with unknown reasons. At the follow-up, after 6 months, 24 participants $(67 \%)$ of the intervention and $24(67 \%)$ of the control group filled in all questionnaires. There were no significant differences between the intervention and control group on baseline on demographic variables or internet-skills. Furthermore, there were no differences between the completers and non-completers on demographic and illness-related data on baseline data.

\section{Primary outcome: Self-efficacy}

No significant differences between the intervention and control group were found on self-efficacy at 3 and 6 months $(p=0.136)$ (see Tables 3 and 4).

\section{Secondary outcomes}

We found no significant differences between the two groups on the secondary outcomes. Results on health care use showed that participants of both groups have had a consultation with a transition nurse. Considering the consultations with the pediatrician or rheumatologist, the median score of the intervention group was 3 (min 0 - max 28), where the median score of the control group was 3.5 ( $\min 0-\max 28)$. No differences were found between the control and intervention group on absenteeism of school or work. The use of biologicals at baseline was higher in the control group (31,3\%) compared to the intervention group $(11,4 \%)$ (see Table 5).

\section{Qualitative outcomes}

Within the Chat, modeling and sharing experiences were recognized as the most frequently expressed interaction. In addition, support and encouragement were also given. In total, 55 individual goals were formulated by the 32 participants at the start. However, a further 112 personal goals were added during the intervention due to personal reflection or increased awareness. Most formulated goals were related to 'improve and maintain balance during the day', 'setting and recognizing boundaries', 'improving communication with others', and 'coping with incomprehension'. Additionally, goals like 'increasing knowledge about the disease,' 'coping with emotional (fear, uncertainly) and psychical consequences (pain, fatigue)' and 'fitting treatment advice for daily life' were formulated.

A total of 145 personal achievements were categorized into: 'gaining insight and awareness,' 'making determined, informed choices,' 'personal influence' 'understanding' and 'new goals for the future'.

Their own learning performance was rated with a mean score of $7.1(\min 6, \max 8.5$; on a scale $0-10)$. The four participants with a self-appointed grade of 6 , did not always relate the learned personal achievement to their originally defined goals.

Some of the participants were surprised by the aim and structure of the intervention, 33 of the 35 participants who started the intervention stayed adherent and were active in the Chat and performing their exercises. Two participants stopped due to medical reasons and school activities. All participants appreciated the intervention, especially the input of the trainers. Some remarks were made about the time of the weekly Chats (start time, duration) and the initial pace of the Chat (too slow). Due to 
Table 3 Results linear mixed models for Dutch-ASES, HAQ-DI, pain, well-being, fatigue, disease-activity and heiQ

\begin{tabular}{|c|c|c|c|}
\hline & Source & $\mathrm{F}$ & Sig. \\
\hline \multirow[t]{4}{*}{ Dutch Arthritis Self-efficacy Scale } & Intercept & 1322.47 & 0 \\
\hline & $\mathrm{T}$ & 0.51 & 0.61 \\
\hline & group & 0.17 & 0.68 \\
\hline & $T^{*}$ group & 2.07 & 0.14 \\
\hline \multirow[t]{4}{*}{ Dutch Consensus Health Assessment Questionnaire (HAQ-DI) } & Intercept & 68.32 & 0 \\
\hline & T & 0.21 & 0.81 \\
\hline & group & 0.01 & 0.93 \\
\hline & $T^{*}$ group & 1.26 & 0.29 \\
\hline \multirow[t]{4}{*}{ Perceived pain } & Intercept & 141.02 & 0 \\
\hline & $\mathrm{T}$ & 1.34 & 0.27 \\
\hline & group & 0.28 & 0.60 \\
\hline & $T^{*}$ group & 0.25 & 0.78 \\
\hline \multirow[t]{4}{*}{ Perceived well-being } & Intercept & 386.33 & 0 \\
\hline & $\mathrm{T}$ & 0.88 & 0.42 \\
\hline & group & 0.73 & 0.40 \\
\hline & $T^{*}$ group & 2.50 & 0.09 \\
\hline \multirow[t]{4}{*}{ Perceived fatigue } & Intercept & 401.63 & 0 \\
\hline & $\mathrm{T}$ & 1.63 & 0.21 \\
\hline & group & 0.43 & 0.51 \\
\hline & $T^{*}$ group & 0.21 & 0.81 \\
\hline \multirow[t]{4}{*}{ Perceived disease activity } & Intercept & 146.02 & 0 \\
\hline & $\mathrm{T}$ & 1.45 & 0.24 \\
\hline & group & 0.16 & 0.69 \\
\hline & $T^{*}$ group & 2.12 & 0.13 \\
\hline \multicolumn{4}{|l|}{ Health Education Impact Questionnaire (heiQ) } \\
\hline \multirow[t]{4}{*}{ Health directed activity } & Intercept & 2011.89 & 0 \\
\hline & $\mathrm{T}$ & 0.33 & 0.72 \\
\hline & group & 1.15 & 0.29 \\
\hline & $T^{*}$ group & 1.66 & 0.20 \\
\hline \multirow[t]{4}{*}{ Positive and active engagement in life } & Intercept & 3936.64 & 0 \\
\hline & $\mathrm{T}$ & 0.05 & 0.95 \\
\hline & group & 1.61 & 0.21 \\
\hline & $T^{*}$ group & 0.61 & 0.55 \\
\hline \multirow[t]{4}{*}{ Emotional distress } & Intercept & 909.73 & 0 \\
\hline & $\mathrm{T}$ & 0.21 & 0.81 \\
\hline & group & 0.02 & 0.90 \\
\hline & $T^{*}$ group & 0.43 & 0.66 \\
\hline \multirow[t]{4}{*}{ Self-monitoring and insight } & Intercept & 6216.50 & 0 \\
\hline & $\mathrm{T}$ & 1.39 & 0.26 \\
\hline & group & 0.83 & 0.37 \\
\hline & $T^{*}$ group & 0.92 & 0.40 \\
\hline \multirow[t]{3}{*}{ Constructive attitude and approaches } & Intercept & 3941.58 & 0 \\
\hline & $\mathrm{T}$ & 0.17 & 0.85 \\
\hline & group & 0.08 & 0.78 \\
\hline
\end{tabular}


Table 3 Results linear mixed models for Dutch-ASES, HAQ-DI, pain, well-being, fatigue, disease-activity and heiQ (Continued)

\begin{tabular}{|c|c|c|c|}
\hline & Source & $\mathrm{F}$ & Sig. \\
\hline & $T^{*}$ group & 0.91 & 0.41 \\
\hline \multirow[t]{4}{*}{ Skills and technique acquisition } & Intercept & 2534.79 & 0 \\
\hline & T & 1.06 & 0.35 \\
\hline & group & 0.70 & 0.41 \\
\hline & $T^{*}$ group & 1.26 & 0.29 \\
\hline \multirow[t]{4}{*}{ Social integration and support } & Intercept & 2328.77 & 0 \\
\hline & T & 1.22 & 0.31 \\
\hline & group & 0.50 & 0.48 \\
\hline & $T^{*}$ group & 1.15 & 0.32 \\
\hline \multirow[t]{4}{*}{ Health service navigation } & Intercept & 2907.22 & 0 \\
\hline & T & 0.25 & 0.78 \\
\hline & group & 2.29 & 0.14 \\
\hline & $T^{*}$ group & 1.83 & 0.17 \\
\hline
\end{tabular}

$F$ statistic, $T$ Time, $T$ *group interaction time and group, Sig significance

technical problems (slow download speed), not every video led to the outcome that was hoped for.

\section{Discussion}

In this RCT on the effectiveness of the web-based selfmanagement intervention Challenge your arthritis among young adults with JIA, no significant differences were found between the intervention group and the control group on self-efficacy, quality of life (QoL), and selfmanagement. On the other hand, participants of the intervention group rated their personal achievements within the intervention positively, and adherence and appreciation of their own learning experience was high.

There are some possible explanations for not identifying significant improvements on the patient reported quantitative measurements. Firstly, both control and intervention groups registered relatively high baseline scores on the domains of self-efficacy, self-management and QoL, so there was little room for improvement. This could have been influenced by the setting of the hospitals were the participants of this study were recruited. Both university hospitals have a special transition outpatient clinic and a multidisciplinary team and are known as large, tertiary care centers in the Netherlands where the focus already lies on guidance towards selfmanagement. Also, both groups were under treatment by a pediatrician, rheumatologist, or transition nurse, receiving medical treatment, and rated themselves relatively low on disease-activity. Secondly, although we chose as outcome measure 'self-efficacy', based on the theoretical fundament of the web-based intervention, one might question if this outcome is acceptable to measure the concept of self-management, considering the age and needs of the young adult. To measure selfefficacy, we used the Dutch-ASES, a questionnaire, developed for adult patients, suffering from a rheumatic disease. As we know from studies on transitional care [9-12] but also from studies on growing up with a chronic disease' $[4,8,11]$, young adults experience other difficulties in managing arthritis in daily life and have other needs compared to the adult group. So it is possible that not only the concept but also the language and aim of the adult self-efficacy scale did not fit with this age group and was therefore not sensitive to change. Clearly, interchangeability of a child and adult questionnaire, measuring the same concept, can be problematic. The absence of questionnaires measuring the concept of self-management from the perspective of young adult's group was also recognized in the study of van Pelt [33]. More research is needed on how to measure the concept of self-management and the meaning of the concept, based on the views of young adults.

Finally, a response shift could have influenced the outcomes of this study. A response shift is defined as 'a change in the meaning of one's self evaluation of a target construct as a result of recalibration' [34] and is recognized as an influencing factor to the outcomes of educational and behavioral interventions. Relatively high scores at baseline could be explained by unawareness of already existing self-management related behavior, since analyses of Chats revealed that participants gained awareness, increased influence on their own situation, and made more informed decisions. It is unknown to what extent the process of awareness had also taken place as a consequence of the usual care both groups received.

The personal goals, set by the participants of the intervention group, reflected the aim of the intervention, and the needs and real-life issues of young adults with JIA, which are known from literature on these subjects $[4,10,11,16]$. During the intervention, personal goals 
Table 4 Results on Dutch Arthritis Self-efficacy Scale (DutchASES), Pain, Wellbeing, Fatigue, Disease Activity, HAQ-DI, HeiQ, based on linear mixed models

\begin{tabular}{ccc}
\hline & Intervention group & Control group \\
Mean $(95 \% \mathrm{Cl})$ & Mean $(95 \% \mathrm{Cl})$ \\
\hline
\end{tabular}

Dutch-Arthritis Self-efficacy Scale ${ }^{a}$

$\begin{array}{lll}\text { T0 } & 6.67(6.11-7.23) & 6.99(6.38-7.59) \\ \text { T1 } & 6.67(6.41-7.54) & 6.80(6.17-7.40) \\ \text { T2 } & 6.51(5.88-7.15) & 6.84(6.19-7.50)\end{array}$

Perceived Pain ${ }^{\mathrm{b}}$

$\begin{array}{lll}\text { T0 } & 3.19(2.39-3.98) & 3.06(2.23-3.89) \\ \text { T1 } & 3.59(2.69-4.50) & 3.11(2.15-4.07) \\ \text { T2 } & 3.65(2.76-4.55) & 3.38(2.44-4.32)\end{array}$

Perceived Wellbeing ${ }^{b}$

$\begin{array}{lll}\text { T0 } & 4.59(3.82-5.36) & 4.24(3.44-5.03) \\ \text { T1 } & 4.93(4.25-5.62) & 4.03(3.29-4.76) \\ \text { T2 } & 4.12(3.28-4.96) & 4.24(3.36-5.12)\end{array}$

Perceived Fatigue ${ }^{\mathrm{b}}$

$\begin{array}{lll}\text { T0 } & 5.36(4.55-6.16) & 5.05(4.21-5.89) \\ \text { T1 } & 5.45(4.66-6.23) & 4.95(4.11-5.79) \\ \text { T2 } & 4.94(4.09-5.79) & 4.75(3.86-5.64)\end{array}$

Perceived Disease Activity

$\begin{array}{lll}\text { T0 } & 3.31(2.57-4.06) & 3.01(2.23-3.79) \\ \text { T1 } & 3.70(2.81-4.58) & 3.02(2.08-3.97) \\ \text { T2 } & 3.42(2.49-4.36) & 3.73(2.75-4.71)\end{array}$

Dutch Consensus Health Assessment Questionnaire (HAQ-DI)

$\begin{array}{lll}\text { T0 } & 0.66(0.46-0.87) & 0.62(0.40-0.85) \\ \text { T1 } & 0.67(0.44-0.90) & 0.59(0.34-0.83) \\ \text { T2 } & 0.62(0.37-0.87) & 0.70(0.44-0.97)\end{array}$

Health Education Impact Questionnaire (heiQ) ${ }^{\text {d }}$

$\begin{array}{ll}\text { Health directed activity } & \\ \text { T0 } & 2.98(2.78-3.18) \\ \text { T1 } & 3.13(2.92-3.33) \\ \text { T2 } & 3.08(2.85-3.32)\end{array}$

Positive and active engagement in life

TO

$\mathrm{T} 1$

$\mathrm{T} 2$

$3.25(3.12-3.38)$

$3.30(3.13-3.47)$

$3.28(3.09-3.47)$

Emotional distress

TO

$\mathrm{T} 1$

$2.00(1.84-2.16)$

$1.93(1.73-2.12)$

$\mathrm{T} 2$

$1.99(1.74-2.24)$

Selfmonitoring and insight
$2.94(2.72-3.16)$

$2.86(2.64-3.07)$

$2.96(2.72-3.21)$

$3.18(3.04-3.32)$

$3.11(2.93-3.29)$

$3.16(2.96-3.36)$

$1.97(1.79-2.14)$

$1.99(1.78-2.20)$

$2.01(1.75-2.27)$

$3.01(2.87-3.16)$

$3.04(2.88-3.20)$

$2.99(2.84-3.13)$
Table 4 Results on Dutch Arthritis Self-efficacy Scale (DutchASES), Pain, Wellbeing, Fatigue, Disease Activity, HAQ-DI, HeiQ, based on linear mixed models (Continued)

\begin{tabular}{ccc}
\hline & $\begin{array}{l}\text { Intervention group } \\
\text { Mean }(95 \% \mathrm{Cl})\end{array}$ & $\begin{array}{c}\text { Control group } \\
\text { Mean }(95 \% \mathrm{Cl})\end{array}$ \\
\hline Constuctive attitude and approaches & \\
T0 & $3.29(3.14-3.43)$ & $3.33(3.17-3.49)$ \\
T1 & $3.34(3.16-3.51)$ & $3.23(3.05-3.41)$ \\
T2 & $3.28(3.10-3.47)$ & $3.26(3.06-3.45)$
\end{tabular}

Skills and technique acquisition

$\begin{array}{lll}\text { T0 } & 2.83(2.65-3.00) & 2.85(2.66-3.04) \\ \text { T1 } & 3.00(2.81-3.20) & 2.81(2.61-3.01) \\ \text { T2 } & 3.02(2.80-3.23) & 2.90(2.68-3.11)\end{array}$

Social integration and support

$\begin{array}{lll}\text { T0 } & 3.10(2.91-3.29) & 3.11(2.90-3.31) \\ \text { T1 } & 3.20(3.01-3.39) & 3.10(2.90-3.30) \\ \text { T2 } & 3.15(2.93-3.37) & 2.97(2.74-3.20) \\ \text { Health service navigation } & & \\ \text { T0 } & 3.16(3.01-3.31) & 3.12(2.96-3.29) \\ \text { T1 } & 3.28(3.09-3.46) & 3.03(2.84-3.23) \\ \text { T2 } & 3.31(3.10-3.52) & 3.06(2.84-3.28)\end{array}$

TO baseline, $T 13$ months after baseline, $T 26$ months after baseline a measured on a scale from 1 to 10 (1 (very unconfident) to 10 (highly confident)

${ }^{b}$ measured on a NRS scale from 0 to 10 (the higher the score, the more pain, fatigue or disease activity and the worse general well-being)

cmeasured on a scale from 0 to 3 ( 0 (no effort) to 3 (impossible)

${ }^{d}$ measured on a scale from 1 to 4 ( 1 (not all true) to 4 (exactly true)

were added which can be seen as a result of increased awareness of needs. In a study on health care transition in rheumatology [12], awareness is recognized as an important factor towards autonomy. Obtaining and increasing autonomy is, in this study, seen as an important psycho-social developmental task of adolescence. Analyses of the interactions in the Chat revealed that many experiences and strategies were shared, and support and encouragement were mutually exchanged. Sharing experiences and strategies to solve problems, and exchanging support and encouragement are recognized as active coping styles and predictors for psychological adjustment in young adults [35]. Stimulating the use of these styles may prevent developmental problems in psychosocial functioning.

The aim of the intervention was to enhance the young adults' self-management in coping with JIA. The qualitative results expose that the intervention 'delivers what it has to deliver' and suggest that the intervention fits the needs of this group. These qualitative results, as well as other studies on needs assessments among young adults with JIA $[4,8,9]$, point out the importance of paying attention to the complexity of managing medical needs, 
Table 5 Absenteeism, health care use and medication use

\begin{tabular}{|c|c|c|c|c|}
\hline & \multicolumn{2}{|c|}{ Intervention group } & \multicolumn{2}{|c|}{ Control group } \\
\hline & & $\mathrm{n}$ & & $\mathrm{n}$ \\
\hline \multicolumn{5}{|l|}{ Absenteeism of school/work (days, previous month) } \\
\hline T1: median (min-max) ${ }^{a}$ & $0.00(0-10)$ & 30 & $0.00(0-10)$ & 27 \\
\hline T2: median $(\min -\max )^{\mathrm{b}}$ & $0.00(0-20)$ & 25 & $0.00(0-30)$ & 24 \\
\hline \multicolumn{5}{|l|}{ Frequency of health use (whole period) } \\
\hline Consultation Pediatrician/rheumatologist, median (min-max) & $3(0-11)$ & & $3.5(0-28)$ & \\
\hline Consultation Transition clinical nurse, median (min-max) & $1(0-7)$ & & $0(0-10)$ & \\
\hline Day-care center, median (min-max) & $0(0-11)$ & & $0(0-8)$ & \\
\hline \multicolumn{5}{|l|}{ Medication use } \\
\hline \multicolumn{5}{|l|}{ Non Steroid Anti-rheumatic Drug (NSAID) } \\
\hline T0: $n(\%)$ & $12(34.3 \%)$ & 35 & $9(28.1 \%)$ & 32 \\
\hline T1: n (\%) & $15(42.9 \%)$ & 35 & 10(31.3\%) & 32 \\
\hline T2: n (\%) & $12(34.3 \%)$ & 35 & $8(25.0 \%)$ & 32 \\
\hline \multicolumn{5}{|l|}{ Disease Modifying Anti Rheumatic Drug (DMARD) } \\
\hline T0: n (\%) & $19(54.3 \%)$ & 35 & $16(50.0 \%)$ & 32 \\
\hline T1: n (\%) & $19(54.3 \%)$ & 35 & $15(46.9 \%)$ & 32 \\
\hline T2: n (\%) & 16(45.7\%) & 35 & $11(34.4 \%)$ & 32 \\
\hline \multicolumn{5}{|l|}{ Biologicals } \\
\hline T0: n (\%) & $4(11.4 \%)$ & 35 & $10(31.3 \%)$ & 32 \\
\hline T1: n (\%) & $7(20 \%)$ & 35 & 10(31.3\%) & 32 \\
\hline T2: n (\%) & $7(20 \%)$ & 35 & $8(25 \%)$ & 32 \\
\hline \multicolumn{5}{|l|}{ Medication to reduce pain (paracetamol) } \\
\hline T0: n (\%) & $6(17.1 \%)$ & 35 & $5(15.6 \%)$ & 32 \\
\hline T1: n (\%) & $2(5.7 \%)$ & 35 & $4(12.5 \%)$ & 32 \\
\hline T2: n (\%) & $2(5.7 \%)$ & 35 & $5(15.6 \%)$ & 32 \\
\hline
\end{tabular}

a Mann-Whitney U (Asymp.Sig (2-tailed)) $=313.50(0.09)$

${ }^{\mathrm{b}}$ Mann-Whitney U (Asymp.Sig (2-tailed) $)=284.00(0.69)$

together with developmental aspects and the drive towards independence. The web-based intervention is appreciated by young adults and can be a valuable aid for both young adults and health care professionals in order to support and improve self-management. The intervention could be valuable in delivering eHealth instead of face-to-face self-management support for young patients who live far from the hospital. Further research is needed to determine which patient benefits most from online selfmanagement support. Furthermore, some adjustments have to be made. Future participants should be better informed about the aim and the structure of the intervention. Additionally, support should be provided to identify the personal needs and goals they want to achieve. This can prevent potential dropout and provide an early indication of those patients who will benefit the most. Contact with the peer trainer before registering for the intervention can be helpful in this process and can improve the effectiveness of the intervention.
There are some limitations to our study that should be mentioned. Firstly, we recruited participants from two large tertiary centres in the Netherlands. Some participants expressed that they participated because they had a good relationship with their doctor. This could have affected their results positively and therefore generalizing the results may not be entirely possible. Secondly, we chose patient reported outcomes (PROs) to capture the young patients' perspectives on the effectiveness of the intervention. Measuring and describing clinical outcomes with, for example, the JADAS (for patients < 18 years old) or the DAS (for patients $>18$ years old) could have been a valuable contribution, but as discussed before, interchangeability of a child and adult questionnaire is problematic, Thirdly, the qualitative results are only representative of the young adults who participated in the intervention group; we did not study these outcomes in the control group. Finally, although the predetermined calculated number of patients was 
included, there was some drop-out in the follow-up leading to a small sample size at the end of the study. However, mixed-method analyses were used in which drop-outs were taken into account [36].

\section{Conclusions}

In our study on the effectiveness of the web-based intervention Challenge your arthritis for young adults with JIA, we did not find improvement of self-efficacy, selfmanagement, and quality of life. However the intervention was regarded to be a valuable and appreciated aid to influence an active coping style by sharing experiences, enhancing social support, and increasing autonomy and goal-setting behavior. More research is needed on how to measure the added value of this intervention/ self-management in this group, and on what meaning young adults themselves give to the concept of selfmanagement.

\begin{abstract}
Abbreviations
CONSORT: The Consolidated Standards of Reporting Trials; DMARD: Disease Modifying Anti Rheumatic Drug; Dutch-ASES: Dutch-Arthritis Self-Efficacy Scale; HAQ-DI: Dutch Consensus Health Assessment Questionnaire Disability Index; HeiQ: Health Education Impact Questionnaire; JIA: Juvenile Idiopathic Arthritis; NRS: Numerical Rating Scale; NSAID: Non Steroid Anti Inflammatory Drug; QoL: Quality of life; RCT: Randomized Controlled Trial; SPSS: Statistical Package for the Social Sciences
\end{abstract}

\section{Acknowledgements}

Thank you to all the patients who participated in this study. We thank Kees Knulst and Marjolein de Hair for their help with the data analyses and Ischa Kummeling, Andy Walker, Tessa Brassé and Anna van der Zalm for their help, checking the manuscript on grammar.

\section{Availability of data and materials}

All data generated or analyzed during this study are included in this article.

\section{Funding}

This research has no sources of funding to declare.

\section{Authors' contributions}

JA, HVO, AAK, BP and JWJB designed the study. JA, AAK, BP and PvP collected the data. JA and NdBN analysed the data under supervision of $\mathrm{HvO}, \mathrm{AAK}, \mathrm{BP}$ and JWJB. JA, HvO, NdB and AAK produced the initial draft and all authors contributed to subsequent drafts and approved the final version.

\section{Ethics approval and consent to participate}

Approval of the Medical Ethical review board of the University Medical Center Utrecht in the Netherlands was obtained prior to start at each study site (reference number is $11-363 / K$ ). Written informed consent was obtained from each participant (or parents/guardian of young adults between the age of 16-18 years old), participating in this study.

\section{Consent for publication}

The consent to publish has been obtained from the participants (or legal parents or guardians for children) to report individual patient data.

\section{Competing interests}

The authors declare that they have no competing interests.

\section{Publisher's Note}

Springer Nature remains neutral with regard to jurisdictional claims in published maps and institutional affiliations.

\section{Author details}

'Department Rheumatology \& Clinical Immunology HPN D02.244, University Medical Center Utrecht, PO Box 85090, 3508 GA Utrecht, the Netherlands. ${ }^{2}$ Department Dermatology and Allergology HPN D02.244, University Medical Center Utrecht, PO Box 85090, 3508 GA Utrecht, the Netherlands. ${ }^{3}$ Department of Rheumatology \& Clinical Immunology HPN F02.127, University Medical Center Utrecht, PO Box 85090, 3508 GA Utrecht, the Netherlands. ${ }^{4}$ Department of Pediatric Immunology, Erasmus MC, Department of Rheumatology, University Medical Center Utrecht, PO Box 2040, Room Nb 852, 3000 GA Rotterdam, Netherlands. ${ }^{5}$ Department of Pediatric Immunology, University Medical Center Utrecht, PO Box 85090, 3508 AB Utrecht, Netherlands. ${ }^{6}$ Department Rheumatology \& Clinical Immunology, HPN D02.244, University Medical Center Utrecht, PO Box 85500, 3500 GA Utrecht, the Netherlands.

Received: 15 February 2017 Accepted: 5 October 2017

Published online: 13 October 2017

\section{References}

1. Gray NJ, Klein JD, Noyce PR, et al. Health information-seeking behaviour in adolescence: the place of the internet. Soc Sci Med. 2005;60:1467-78.

2. Stinson J, Wilson R, Gill N, et al. A systematic review of internet-based selfmanagement interventions for youth with health conditions. J Pediatr Psychol. 2009;34:495-510.

3. Eland-de Kok P, van Os-Medendorp H, Vergouwe-Meijer A, et al. A systematic review of the effects of e-health on chronically ill patients. J Clin Nurs. 2011;20:2997-3010.

4. Stinson JN, Toomey PC, Stevens BJ, et al. Asking the experts: exploring the self-management needs of adolescents with arthritis. Arthritis Rheum. 2008:59:65-72.

5. Stinson JN, McGrath PJ, Hodnett ED, et al. An internet-based self-management program with telephone support for adolescents with arthritis: a pilot randomized controlled trial. J Rheumatol. 2010:37:1944-52.

6. Ammerlaan JJ, Scholtus LW, Drossaert CH, et al. Feasibility of a website and a hospital-based online portal for young adults with juvenile idiopathic arthritis: views and experiences of patients. JMIR Res Protoc. 2015;4:e102.

7. van Pelt P, Drossaert C, Kruize A, et al. Use and perceived relevance of health related internet sites and online contact with peers among young people with juvenile idiopathic arthritis. Rheumatology. 2015;54:1833. (accepted)

8. Sawyer SM, Aroni RA. Self-management in adolescents with chronic illness. What does it mean and how can it be achieved? Med J Aust. 2005;183:405-9.

9. Ammerlaan JW, Scholtus LW, Bijlsma HJ, et al. An urge for change: transitional care for young adults with juvenile idiopathic arthritis. Patient Educ Couns. 2013;92:127.

10. Howland S, Fisher K. Looking through the patient lens - improving best practice for young people with juvenile idiopathic arthritis transitioning into adult care. Spring. 2015;4:111. -015-0888-8. eCollection 2015

11. Bloom SR, Kuhlthau K, Van Cleave J, et al. Health care transition for youth with special health care needs. J Adolesc Health. 2012;51:213-9.

12. Wells $\mathrm{CK}, \mathrm{McM}$ orris $\mathrm{BJ}$, Horvath $\mathrm{KJ}$, et al. Youth report of healthcare transition counseling and autonomy support from their rheumatologist. Pediatr Rheumatol Online J. 2012:10:36. -0096-10-36

13. Prakken B, Albani S, Martini A. Juvenile idiopathic arthritis. Lancet. 2011;377:2138-49.

14. Wagner-Weiner L. Pediatric rheumatology for the adult rheumatologist. J Clin Rheumatol. 2008;14:109-19.

15. Tucker LB, Cabral DA. Transition of the adolescent patient with rheumatic disease: issues to consider. Rheum Dis Clin N Am. 2007;33:661-72.

16. Shaw KL, Southwood TR, McDonagh JE, et al. User perspectives of transitional care for adolescents with juvenile idiopathic arthritis. Rheumatology (Oxford). 2004:43:770-8

17. Lawson EF, Hersh AO, Applebaum MA, et al. Self-management skills in adolescents with chronic rheumatic disease: a cross-sectional survey. Pediatr Rheumatol Online J. 2011;9:35.

18. Barlow J, Wright C, Sheasby J, et al. Self-management approaches for people with chronic conditions: a review. Patient Educ Couns. 2002;48:177-87.

19. Ammerlaan J, van Os-Medendorp H, Scholtus L, et al. Feasibility of an online and a face-to-face version of a self-management program for young adults with a rheumatic disease: experiences of young adults and peer leaders. Pediatr Rheumatol Online J. 2014;12:10. -0096-12-10 
20. Bandura A. Self-efficacy: toward a unifying theory of behavioral change. Psychol Rev. 1977;84:191-215.

21. Lenzen $S A$, Daniels $R$, van Bokhoven MA, et al. Setting goals in chronic care: shared decision making as self-management support by the family physician. Eur J Gen Pract. 2015;21:138-44.

22. Holloway I, Wheeler S. Qualitative research in nursing. Oxford: Blackwell Publishing; 2002.

23. Ringold S, Weiss PF, Beukelman T, et al. 2013 update of the 2011 American College of Rheumatology Recommendations for the treatment of juvenile idiopathic arthritis. Arthritis Rheum. 2013;65:2499-512.

24. Mueller A, Hartmann M, Mueller $\mathrm{K}$, et al. Validation of the arthritis self-efficacy short-form scale in German fibromyalgia patients. Eur J Pain. 2003;7:163-71.

25. Ammerlaan JW, van Os-Medendorp H, Sont JK, et al. Validation of the dutch version of the health education impact questionnaire (HEIQ) and comparison of the Dutch translation with the English, German and French HEIQ. Health Qual Life Outcomes. 2017;15:28.

26. Osborne RH, Elsworth GR, Whitfield K. The health education impact questionnaire (heiQ): an outcomes and evaluation measure for patient education and self-management interventions for people with chronic conditions. Patient Educ Couns. 2007;66:192-201.

27. Boers M, Jacobs JW, van Vliet Vlieland TP, et al. Consensus Dutch health assessment questionnaire. Ann Rheum Dis. 2007;66:132-3.

28. Englbrecht $\mathrm{M}$, Tarner $\mathrm{IH}$, van der Heijde DM, et al. Measuring pain and efficacy of pain treatment in inflammatory arthritis: a systematic literature review. J Rheumatol Suppl. 2012;90:3-10.

29. Vaismoradi M, Turunen $\mathrm{H}$, Bondas T. Content analysis and thematic analysis: implications for conducting a qualitative descriptive study. Nurs Health Sci. 2013;15:398-405.

30. Moher D, Hopewell S, Schulz KF, et al. CONSORT 2010 explanation and elaboration: updated guidelines for reporting parallel group randomised trials. Int J Surg. 2012;10:28-55.

31. Niedermann K, de Bie RA, Kubli R, et al. Effectiveness of individual resourceoriented joint protection education in people with rheumatoid arthritis. A randomized controlled trial. Patient Educ Couns. 2011;82:42-8.

32. Field A. Discovering statistics using IBM SPSS statistics. London: Sage Publications; 2013.

33. van Pelt PA, Kruize AA, Goren SS, et al. Transition of rheumatologic care, from teenager to adult: which health assessment questionnaire can be best used? Clin Exp Rheumatol. 2010;28:281-6.

34. Osborne RH, Hawkins M, Sprangers MA. Change of perspective: a measurable and desired outcome of chronic disease self-management intervention programs that violates the premise of preintervention/ postintervention assessment. Arthritis Rheum. 2006;55:458-65.

35. Meijer SA, Sinnema G, Bijstra JO, et al. Coping styles and locus of control as predictors for psychological adjustment of adolescents with a chronic illness. Soc Sci Med. 2002;54:1453-61.

36. DeSouza CM, Legedza AT, Sankoh AJ. An overview of practical approaches for handling missing data in clinical trials. J Biopharm Stat. 2009;19:1055-73.

\section{Submit your next manuscript to BioMed Central and we will help you at every step:}

- We accept pre-submission inquiries

- Our selector tool helps you to find the most relevant journal

- We provide round the clock customer support

- Convenient online submission

- Thorough peer review

- Inclusion in PubMed and all major indexing services

- Maximum visibility for your research

Submit your manuscript at www.biomedcentral.com/submit

) Biomed Central 